\title{
Espelho mágico: produção e recepção de imagens de empregadas domésticas em uma telenovela brasileira*
}

\author{
Renata Mourão Macedo**
}

\section{Resumo}

Este artigo analisa aspectos relacionados à produção $e$ à recepção de imagens de empregadas domésticas na televisão brasileira, discutindo, em especial, a telenovela Cheias de Charme (Globo, 2012, 19h30). Apresentando três empregadas domésticas como protagonistas, essa novela incorporou transformações associadas a essas trabalhadoras ao encenar o movimento de ascensão social para a chamada "classe C", processo socioeconômico adensado na primeira década dos anos 2000. Nesse contexto, este artigo discute como a telenovela relacionou empregadas domésticas, mobilidade social e "autoestima", revalorizando essas trabalhadoras para, no mesmo passo, reconstruir o discurso sobre mulheres das classes populares enquanto consumidoras.

Palavras-chave: Empregadas domésticas, Telenovelas, Consumo, Mobilidade Social, "Classe C".

* Recebido para publicação em 10 de julho de 2014, aceito em 21 de julho de 2016. Esta pesquisa é resultado de dissertação de mestrado defendida junto ao Programa de Pós-Graduação em Antropologia Social da USP em 2013, sob orientação da Dra. Heloisa Buarque de Almeida (Macedo, 2013). A realização da pesquisa contou com auxílio da Fapesp. Agradeço a Julia Goyatá e Dimitri Pinheiro da Silva pelas críticas e sugestões para o desenvolvimento deste artigo.

** Doutoranda em Antropologia Social na Universidade de São Paulo e pesquisadora do Numas/USP, São Paulo, SP, Brasil. renatagmourao@hotmail.com 
Magic Mirror: Production and Reception of Images of Domestic Workers in a Brazilian Soap Opera

\begin{abstract}
The article discusses aspects related to the production and reception of images of domestic workers on Brazilian television, discussing in particular the soap opera Cheias de Charme (Globo, 2012, 7:30pm). Introducing three house cleaners as protagonists, this program has incorporated changes associated with these workers while staging the movement of social ascension to "class C", socioeconomic process that began in the first decade of the 2000s. In this context, this paper discusses how the soap opera related domestic workers, social mobility and "self-esteem", revaluing these workers to rebuild the discourse on women of the popular classes as spectators, but now recognizing her outstanding role as consumers.
\end{abstract}

Keywords: Domestic Workers, Soap opera, Consume, Social Mobility, Social Classes. 


\title{
Introdução
}

\begin{abstract}
Todo dia acordo cedo/ moro longe do emprego/ quando chego do serviço, quero meu sofá/ Tá sempre cheia a condução/ eu passo pano, esfrego o chão/ a outra vê defeito até onde não há/ [...]/ Levo vida de empreguete, eu pego as sete/ Fim de semana é salto alto e ver no que vai dar/ Um dia compro apartamento, viro socialite/ Toda boa vou com meu ficante viajar [letra de "Vida de Empreguete"].
\end{abstract}

Exibida em 2012 pela Rede Globo, em contexto socioeconômico favorável que levou a uma ativação do mercado interno e ampliação do mercado consumidor brasileiro, a telenovela Cheias de Charme alçava empregadas domésticas ao papel de protagonistas. Diferente de outras imagens recorrentes na teledramaturgia brasileira sobre essas profissionais, tais trabalhadoras foram então representadas como consumidoras ativas, com grandes expectativas de ascensão social, conforme a música tema da novela, intitulada "Vida de Empreguete", explicitava.

Deve-se lembrar que desde o início da produção das telenovelas brasileiras, na década de 1970, personagens empregadas domésticas estiveram presentes. Quase anuladas como figurantes que abrem portas e atendem telefones, cobiçadas como objeto de desejo erótico, ridicularizadas como representantes típicas das mulheres das classes populares, envolvidas em movimento de ascensão social (em geral dado pelo casamento) ou mesmo como porta vozes de uma visão questionadora dos valores das classes dominantes, as empregadas domésticas foram personagens frequentes nas produções eletrônicas nacionais. Apesar da recorrência de certos estereótipos, transformações nessas personagens foram progressivamente incorporadas pelas mídias que as veiculam. 
Neste artigo, analiso aspectos da produção e da recepção da telenovela Cheias de Charme (Globo, 2012, 19h30) ${ }^{1}$, contrapondoa com outras imagens de empregadas domésticas na televisão brasileira. A propósito, chamo atenção para o fato de que tal novela teve como referência o contexto favorável de mobilidade social de parcela da população brasileira, chamada pelo mercado de "nova classe C" ou "nova classe média", fenômeno adensado no início dos anos 2000 e ainda operante em 2012, momento de exibição da novela. ${ }^{2}$ Nesse contexto, Cheias de Charme esteve vinculada ao projeto mais amplo da Rede Globo de tentar "fidelizar" as telespectadoras das classes populares, agora revalorizadas enquanto consumidoras visibilizadas no mercado.

Por meio de pesquisa de campo etnográfica realizada no período com empregadas domésticas que trabalham na cidade de São Paulo $^{3}$, discuto processos ligados à produção e à circulação

1 A trama de Cheias de Charme narrou a história de três empregadas domésticas - Maria da Penha, Maria do Rosário e Maria Aparecida, interpretadas pelas atrizes Tais Araújo, Leandra Leal e Isabelle Drummond, respectivamente - que ascendem socialmente por meio de um grupo musical, chamado "As Empreguetes", após o sucesso da música "Vida de Empreguete". Moradoras da favela do Borralho, em clara referência ao clássico conto de fadas da gata borralheira (Grimm, 2012), as protagonistas lutam contra vilões e adversidades para conquistar o sonho do sucesso. Foi escrita por Izabel de Oliveira e Filipe Miguez, dirigida por Denise Saraceni e contou com a consultoria musical do antropólogo e produtor Hermano Vianna. Para uma análise da trama, conferir Melo (2016), entre outros autores.

2 Segundo Bartelt (2013:4), no ano de 2012, em especial, "houve interessante junção de fatos, formando uma ofensiva de marketing na construção de uma visão sobre a nova classe média brasileira", destacando-se, entre eles, "duas novelas da TV Globo que exibiram pela primeira vez a nova classe média ou classe C como protagonista - "Cheias de Charme" e "Avenida Brasil" -, ocupando, concomitantemente e durante meses, os horários das 19 e das 21 horas".

${ }^{3}$ Entre 2010 e 2012, foram realizadas 28 entrevistas semiestruturadas com empregadas domésticas mensalistas e diaristas que trabalhavam na cidade de São Paulo. Com 10 trabalhadoras pude aprofundar a pesquisa, realizando uma pesquisa de cunho etnográfico, indo periodicamente em suas residências e nas casas de seus patrões. Foi com essas trabalhadoras que acompanhei a telenovela em questão. 
desse produto cultural (Hall, 2003). ${ }^{4}$ Ainda que parte da pesquisa esteja baseada em um estudo de recepção, no sentido mais usual do termo ${ }^{5}$, optei por realizar uma análise compartilhada, que tenta associar minha interpretação às das mulheres que participaram da pesquisa. Minha proposta é organizar conjuntamente essas diferentes decodificações "negociadas" 6 para a análise de tais imagens.

\title{
1.As expectativas de Rosa: imagens de empregadas domésticas na TV
}

\begin{abstract}
Ana Maria Braga [entrevistadora]: "Vida de Empreguete" é tão dura assim como vocês retratam no clipe?

Penha [empregada]: Olha Ana, difícil mesmo é aturar cara de patroa ignorante que não sabe pedir as coisas com educação.

Sonia [patroa]: Ana, eu acho que nós estamos vivendo uma inversão total de valores, entende? Não somos nós que precisamos das empregadas [...]. Elas é que precisam do emprego, precisam do dinheiro que nós pagamos.

Cida [empregada]: Até parece Dona Sonia, a senhora precisa de mim até pra pegar água!
\end{abstract}

${ }^{4}$ Em texto clássico para os estudos de mídia, Stuart Hall (2003) reformulou o modelo linear da comunicação de massa enfatizando a interligação entre suas diferentes etapas: produção, circulação e recepção. Segundo Hall, embora interligados, tais momentos podem ser relativamente autônomos, de modo que a decodificação de discursos midiáticos pode gerar sentidos diversos daqueles previstos na produção.

${ }^{5}$ A noção de recepção, de maneira geral, refere-se ao deslocamento do olhar para aqueles que recebem determinados produtos culturais. Segundo Varela (2008), o conceito ocupou um lugar importante nos debates contemporâneos em diversas aéreas e relaciona-se com termos vizinhos tais quais leitura, interpretação, público, audiência e consumo.

6 Segundo Hall (2003:379, grifos do autor), "decodificar, dentro da versão negociada, contém uma mistura de elementos de adaptação e de oposição: reconhece a legitimidade das definições hegemônicas para produzir as grandes significações (abstratas), ao passo que, em um nível mais restrito, situacional (localizado), faz suas próprias regras - funciona com as exceções às regras". 
Sonia: Eu sou de um tempo em que os serviçais sabiam o seu lugar!

Cida: Eu esqueci que a senhora pegou a época da escravidão!

Ana Maria Braga: Gente, eu só quis promover aqui uma confraternização...

Chayenne [patroa]: Ana, pare tudo porque agora eu quero falar! Eu sou uma patroa que dou de tudo: eu dou comida, eu dou quartinho, eu dou sabão de coco pra elas se lavarem, eu dou papel higiênico, eu dou copo, prato, talher, tudo separado, sem descontar o salário!

Penha: Agora pra tirar férias, como manda a lei, é um sacrifício! [...]. E ela viaja e quer que eu fique carregando a mala dela. Eu não sou carregadora de mala não! [...]

Quando encontrei a empregada doméstica Rosa ${ }^{7}$ alguns dias após a transmissão dessa cena na televisão, ela estava animada para conversar sobre o assunto. Exibido em Cheias de Charme, em junho de 2012, tal diálogo se ambientou ficcionalmente no programa matinal da apresentadora Ana Maria Braga, também da Rede Globo, que foi incorporado como cenário da novela. Simulando o encontro das três protagonistas - que já haviam ascendido como cantoras de sucesso - e de suas respectivas ex-patroas com a apresentadora, a cena as reunia em uma mesa de café da manhã para conversar sobre o sucesso do clipe "Vida de Empreguete", que as lançara como artistas.

Essa cena, especificamente, havia marcado Rosa. Recordando os disparates defendidos pelas patroas, ela reconstituía os pormenores da cena: "você viu a Chayenne dizendo que dá até quartinho e as empregadas só sabem reclamar?". E com um sorriso indignado, ao mesmo tempo orgulhoso, repetia "você viu o que eu te falei?". Rosa referia-se a conversas anteriores em que debatíamos a profissão de empregada doméstica e as dificuldades enfrentadas pela mulher

7 Os nomes reais de todas as interlocutoras da pesquisa foram substituídos por nomes fictícios a fim de preservar o anonimato. Sobre essa opção em pesquisas antropológicas urbanas, conferir Fonseca (2010). 
pobre, ocasião em que manifestara sua indignação em relação ao baixo status de ambas ${ }^{8}$. Para ela, em relação à profissão, os agravantes seriam a diferenciação das leis trabalhistas - que ainda não obrigava o pagamento de FGTS e seguro-desemprego para a categoria -, e sua desvalorização social, tanto das atividades desempenhadas quanto das profissionais, tratadas por muitas famílias com desigualdade e indiferença.

Diante da veiculação dessa problemática pela televisão, $e$ em especial em uma telenovela, Rosa se mostrava satisfeita. Grande apreciadora dessa mídia, especialmente das novelas da Rede Globo, para essa trabalhadora "o Brasil" precisava conhecer melhor, havia muito tempo, os "preconceitos" e a "desvalorização" a que a empregada doméstica estaria submetida. No passado, ela mesma teve empregadores que pensavam como a personagem Chayenne, que ao oferecerem quarto de empregada, talheres e comida, pensavam serem muito generosos com suas funcionárias. Rosa demonstrava orgulho porque, na cena em questão, diferente do usual na televisão, havia espaço para as empregadas responderem. Em conversas anteriores, ela também revelou insatisfação com os modos pelos quais as empregadas domésticas usualmente eram representadas na televisão, em geral "brincalhonas e irresponsáveis", referindo-se especialmente ao seriado $A$ Diarista (2003, Globo, 22h30). Em março de 2012, na iminência da estreia de Cheias de Charme, já anunciada pela emissora como uma novela que teria empregadas como protagonistas, Rosa se mostrara otimista.

A escolha dessa temática para uma novela da Rede Globo em 2012, entretanto, não foi casual. A transformação identificada por Rosa - no que se refere a uma voz mais ativa para essas

8 A desvalorização do emprego doméstico, o estigma a ele associado e as dificuldades profissionais historicamente enfrentadas por tais profissionais são aspectos amplamente discutidos pela bibliografia produzida nas ciências sociais sobre emprego doméstico. Sobre isso, ver Saffioti (1978), Kofes (2001), Lima e Rezende (2004), Brites (2007), Brites e Picanço (2014), entre outras autoras. Uma análise sobre representações de empregadas domésticas na mídia foi realizada por Rezende (1997). 
personagens - é reveladora de um duplo movimento que deve ser levado em conta. Se, para Rosa, sempre foi tão importante que a televisão, e especialmente as teleficções da Globo, "valorizasse" a empregada doméstica enquanto mulher e profissional, para a televisão, e especialmente para a Globo, aquele momento era especialmente importante para cativar a audiência de Rosa, mantendo-a como telespectadora "fidelizada". Assim, ao transformar empregadas domésticas em protagonistas, essa emissora consolidava seu projeto de revalorizar as classes populares, agora entendidas também como consumidoras da "nova classe média" a serem conquistadas. Impulsionado pela euforia do mercado diante do aumento do poder de consumo de parcela da população a partir de meados dos anos 2000 por um lado, e pela migração das classes médias e altas para a televisão por assinatura ou para outras mídias, por outro, tal projeto foi anunciado abertamente pelos seus produtores e pôde ser verificado em outras produções recentes, conforme veremos a seguir.

\section{Formas de classificação, modos de representação}

De acordo com Esther Hamburger (2005:27), a história da televisão no Brasil pode ser dividida em três períodos, se levadas em conta suas relações com o Estado, os anunciantes e o público. No primeiro, de 1950 a 1969, fase incipiente, predominariam os programas de auditório, teleteatros e novelas importadas. $\mathrm{O}$ segundo, entre 1970 e 1989, seria o período de expansão da televisão no Brasil, do monopólio da Rede Globo e da consolidação das telenovelas como produto principal da emissora, com penetração em quase todos os setores da sociedade. $\mathrm{O}$ terceiro, a partir da década de 1990 até a atualidade, seria o período de diversificação da estrutura $e$ da programação televisiva, com dispersão da audiência para a televisão paga $e$ para outras mídias, ainda que a liderança da Rede Globo, especialmente por meio de suas novelas, fosse mantida. 
Desde o início da produção de novelas pela Rede Globo, o departamento de pesquisa dessa emissora atribuiu grande importância à variável "classe" para conhecer sua audiência. Nas décadas de 1970 e de 1980, embora as novelas fossem consumidas por homens $e$ mulheres de classe sociais diversificadas, as denominadas "classes B" e "C", mas em especial a "mulher da classe C", já eram vistas como espectadoras ideais (Hamburger, 2005; Almeida; Macedo, 2015). Entretanto, apesar do predomínio da linguagem "realista", as tramas priorizaram cenários e personagens das classes médias e altas, sobretudo do universo carioca9. Tal disjunção se explicaria, segundo hipótese de Esther Hamburger, à luz dos critérios utilizados pelas pesquisas na época, que superestimavam a condição social de sua audiência, então imaginada com maiores níveis educacional e de renda. Ou seja, apesar de o departamento de pesquisa da Globo estar ciente do caráter popular de seu público, os critérios de pesquisa e, possivelmente, a falta de interesse dos produtores nos extratos populares da sociedade brasileira, fizeram com que a programação do período - até meados da década de 1990 - fosse direcionada às classes médias e altas. ${ }^{10}$ É importante lembrar que também fora da Rede Globo os consumidores das classes

9 Segundo Hamburger (2005:118), "a diversidade étnica e racial brasileira, a pobreza, a miséria e a violência estiveram praticamente ausentes desse universo 'realista'. As novelas representaram o Brasil como uma ampliação do universo da classe média alta carioca que as fazia à sua imagem e semelhança".

${ }^{10} \mathrm{O}$ caso do SBT traz um contraponto significativo. Conforme analisa Almeida (2003), essa emissora teve sérias dificuldades para conseguir anunciantes em função do seu público, visto como excessivamente popular. Mira (1995) também analisou esse processo: "parece-me que uma das razões do sucesso do grupo Silvio Santos é que ele percebeu a existência de um mercado de consumo popular, investiu e lucrou com o relativo abandono a que este ficou relegado durante os anos 70. Na segunda metade da década, o Grupo penetrou nesse 'espaço vazio' também no âmbito do imaginário. Um espaço que o 'projeto Globo de televisão' deixou aberto, quando optou por uma linha de programas que respondia, basicamente, aos anseios das classes médias em ascensão a partir do final dos anos 60" (Mira, 1995:72). 
populares foram negligenciados, sendo recente sua incorporação sistemática em pesquisas de mercado.

A partir dos anos 2000, a Globo buscou ampliar sua penetração também nas "classes $\mathrm{CD}$ ", processo incentivado pela migração das "classes A e B" para a televisão fechada e para outras mídias. No período de realização da pesquisa aqui relatada, entre 2010 e 2013, tal debate ganhou espaço na imprensa, que noticiou com frequência a guinada da TV Globo em busca da audiência da "nova classe C" ou "nova classe média". ${ }^{11}$

Compreender essa reorientação requer também discutir os sentidos associados às classificações "classe C" $e$ "nova classe média", frequentemente mobilizadas no período. A distribuição da população em classes de renda organizadas em torno de letras (A, $\mathrm{B}, \mathrm{C}, \mathrm{D}$ e $\mathrm{E})$ tem sido usual entre as agências de pesquisa de mercado, o departamento de pesquisa da Globo inclusive. O aumento da importância da "classe C" se insere num contexto de ampliação da mobilidade social que se inicia com o advento do Plano Real, em 1994, e se intensifica em meados dos anos 2000. Segundo alguns especialistas (Neri, 2010:31), a faixa C correspondia a cerca de $35 \%$ da população em 2003, passando para 50,45\% em 2009, ou seja, foram 29 milhões de brasileiros que ascenderam a esse segmento. De acordo com Marcelo Neri, a classe econômica " $\mathrm{C}$ ", ao corresponder então ao segmento médio da população brasileira, poderia ser chamada de "nova classe média".

Apesar do consenso a respeito do incremento da renda e do poder de consumo para parte da população no período do "lulismo" (Singer, 2012), a análise desse processo envolveu disputas teóricas e políticas sobre a ascensão ou não a uma "nova classe média". Partindo de uma concepção sociológica de classe social - em oposição ao discurso das instituições do mercado -,

\footnotetext{
${ }^{11}$ Destaco, por exemplo, as matérias publicadas no jornal Folha de S. Paulo: "Todos querem tirar a nova classe média para dançar" (Marinheiro, 2012); "Atrás da classe C, TV fatura 12\% a mais no semestre" (Jimenez, 2012); "Globo muda telejornal para tentar salvar ibope e atrair classe C" (Feltrin, 2011), entre outras.
} 
Jessé de Souza (2010:324) defendeu que a classificação exclusivamente por renda consistia em uma maneira de desmobilizar o debate político e "eufemizar" a dominação das classes altas no Brasil. Para Souza (2010:327), mobilizando as análises sobre classes sociais de Pierre Bourdieu (2007), essa população em ascensão constituiria na realidade uma "nova classe trabalhadora" que, apesar de possuir três características fundamentais para seu crescimento - disciplina, autocontrole $e$ pensamento prospectivo, contaria ainda com "relativamente pequena incorporação dos capitais impessoais mais importantes da sociedade moderna, capital econômico e capital cultural - o que explica seu não pertencimento a uma classe média verdadeira". Também Celi Scalon e André Salata problematizaram a noção de "nova classe média" ao contrapô-la com a perspectiva sociológica de classes sociais. Baseando-se em classificações sócio-ocupacionais, os autores questionaram a alocação forçada de ocupações manuais (como o emprego doméstico) entre as classes médias. Isso, entretanto, não significa que não houve mudanças nos padrões de renda e consumo. Segundo os autores, ao invés de uma "nova classe média", poderse-ia ponderar "sobre uma parcela da classe trabalhadora que, em relação a certas características, quase exclusivamente os rendimentos, estaria se aproximando dos setores mais baixos das classes médias" (Scalon; Salata, 2012:404).

Apesar da divergência entre cientistas sociais e agências de pesquisa de mercado, esse fenômeno de incremento de renda teve grande repercussão também na Rede Globo. Em entrevista concedida ao jornalista Mauricio Stycer, em 2011, o então diretorgeral da emissora, Octavio Florisbal, explicitou alguns pontos a esse respeito: "estes $80 \%$ das classes C, D e E têm uma vida própria, com características próprias. Nós precisamos atendê-los" (Stycer, 2011). Mantendo a tradição da emissora de não revelar seus métodos de pesquisa, Florisbal demonstrou possuir um conhecimento renovado desses segmentos e, segundo ele, tornava-se efetivamente necessário naquele momento levar em conta essa parcela da população na feitura da programação: 
Isso também muda os hábitos de consumo de mídia. No passado, você não tinha que se preocupar tanto - "estou fazendo uma televisão para todos, mas com foco em classe média". Hoje, não. Atenção. [...] Aquela divisão de que $80 \%$ do público é das classes C, D e E continua, mas eles têm mais presença, mais opinião. Eles ascenderam. [...] Eles têm que estar mais bem representados e identificados na dramaturgia, no jornalismo. [...] Eles querem ter uma linguagem mais simples, para entender melhor (Stycer, 2011).

Ao longo da entrevista, Florisbal reconheceu a existência de certos "estereótipos" comuns até recentemente nas novelas da Globo, que retratavam os personagens populares de maneira menos densa do que os ricos. Tal caracterização, certamente, incidia nas personagens de empregadas domésticas, dezenas delas servindo apenas de figuração, compondo cenários para os dramas da elite. E mesmo nas vezes em que foram protagonistas, como na telenovela Sem Lenço, Sem Documento (1977) ${ }^{12}$, a desigualdade inerente às relações profissionais entre patrões e empregados quase não era problematizada. Isso, no entanto, não significa que as encenações recentes tenham um discurso radical de enfrentamento da desigualdade social, mas que apontam para transformações graduais, porém não menos importantes, em relação à temática.

\footnotetext{
${ }^{12}$ Apesar de pouco lembrada, na década de 1970 a novela Sem Lenço, Sem Documento (Globo, 1977, 19h) apresentou temática e estrutura semelhantes a de Cheias de Charme. Escrita por Mário Prata, contava a história de quatro irmãs que haviam migrado de Olinda $(\mathrm{PE})$ para trabalhar como domésticas no Rio de Janeiro (Memória Globo, 2010).
} 


\section{Discutindo a relação: empregadas domésticas e mídias em Cheias de Charme}

Dando continuidade a uma longa lista de empregadas domésticas já exibidas por telenovelas da Rede Globo desde a década de 1970, Cheias de Charme as fez protagonistas. A trama contava a história de três empregadas domésticas que ascenderam socialmente por meio de um grupo musical chamado "Empreguetes". Embora houvesse reconhecido esforço de adensar as personagens, focalizando sua casa, trabalho $e$ desafios cotidianos - entre eles, o assédio sexual, o preconceito e a luta por direitos trabalhistas -, alguns estereótipos se renovaram: reencenava-se a empregada doméstica sonhadora e sensual, que ascende socialmente por meio de talentos artísticos inesperados. ${ }^{13}$

Visando retratar as expectativas das espectadoras da "nova classe C", Cheias de Charme combinou a representação de uma determinada realidade social - a das empregadas domésticas brasileiras, moradoras de periferias e subúrbios, que enfrentam cotidianamente a desigualdade social -, com uma esfera lúdica, própria ao horário das $19 \mathrm{~h}$. Assim, a combinação entre local (a favela no Rio de Janeiro) e universal (a busca por ascensão social), entre conjuntural (o fenômeno socioeconômico de ascensão do segmento $C$ em meados dos anos 2000) e atemporal (os contos de fadas, tal qual Cinderela ${ }^{14}$ ) fizeram da novela um produto capaz de agradar espectadores de diferentes classes sociais e idades, em especial o público infanto-juvenil ${ }^{15}$.

\footnotetext{
${ }^{13}$ Papel já vivido, por exemplo, pela atriz Zezé Motta em Transas e Caretas, exibida pela Globo em 1984 (Araújo, 2004:234).

${ }^{14}$ Sobre a associação entre feminilidade e princesas, ver o trabalho de Escoura (2012).

${ }^{15}$ Segundo medição realizada pelo Ibope, Cheias de Charme teve média de 30 pontos em São Paulo (IG, 2012), alcançando picos de 44 pontos (Natelinha, 2012). Foi uma das melhores audiências para novelas das $19 \mathrm{~h}$ na Globo desde Da Cor do Pecado, exibida em 2004 que teve 45 pontos de média. Cada ponto equivale, em média, a 60 mil domicílios na capital paulista (IG, 2012).
} 
Todas as trabalhadoras domésticas com as quais tive a oportunidade de conversar $e$ analisar conjuntamente a trama concordaram na avaliação de que Cheias de Charme "foi legal" por trazer para primeiro plano temas desvalorizados como o serviço doméstico e suas questões trabalhistas. Tal dimensão associou-se à reflexão sobre a importância da cultura musical $e$ midiática para o universo popular feminino e urbano, bem trabalhada na trama, especialmente na figura de Fabian (Ricardo Tozzi), "o príncipe das domésticas", certamente uma referência ao lugar que Odair José e Amado Batista ocuparam nos anos de 1970 e 1980 ao compor canções especialmente dedicadas a essas profissionais (Macedo, 2013).

Incluindo uma série de diálogos sobre a necessidade de assinar a carteira de trabalho, tirar férias, folgar no mínimo uma vez por semana, etc, a trama veiculou a temática dos direitos trabalhistas de maneira didática, aproximando-se de um merchandising social, conteúdo em voga nas telenovelas brasileiras desde os anos de 1990 (Hamburger, 2004). Durante a pesquisa de campo, essas discussões trabalhistas foram notadas e, de maneira geral, bem avaliadas. Rosa contou que conversou com algumas amigas de mesma profissão e elas concordaram que a novela "ajudou" a explicar os direitos da empregada e a convencer os patrões que esses direitos devem ser respeitados. Já Luiza concluiu que gostou por um lado, mas se decepcionou por outro. Tomando como exemplo a cena em que a vilã Chayenne, então patroa da empregada doméstica Penha, jogou um prato de sopa em cima dela em uma briga, Luiza disse perceber que era tudo muito exagerado. "A realidade não é assim", refletiu. Relembrando suas últimas três experiências profissionais ${ }^{16}$, Luiza

\footnotetext{
${ }^{16}$ Das três últimas experiências profissionais como doméstica vividas por Luiza, nenhuma terminou bem. Na primeira, preparou o almoço do filho da patroa, mas ele ficou jogando videogame; quando veio comer, reclamou que estava frio. Ela então disse, na frente de sua irmã mais velha, que não iria esquentar porque o havia chamado muitas vezes e ele ignorou. À noite, a irmã contou para a mãe $e$ no dia seguinte ela foi demitida. No segundo emprego, diante de uma enorme quantidade de roupa acumulada para lavar e secar, Luiza resolveu estender um
} 
explicava que, atualmente, as tensões entre patroas e empregadas eram mais veladas, o que as torna ainda mais difíceis de serem julgadas.

De modo geral, ainda que por meio de uma estética "exagerada", conforme a interpretação de Luiza, o debate sobre direitos trabalhistas na telenovela foi inovador para o gênero. Realizado paralelamente em Avenida Brasil (Globo, 21h, 2011), por meio das reivindicações da protagonista Nina - então empregada na casa de sua madrasta Carminha -, o tema da "vingança da empregadinha", conforme denominou Hamburger (2012), teve uma série de repercussões na imprensa e apontou mudanças importantes na caracterização da empregada doméstica na televisão brasileira. Se por décadas a personagem tentou discutir pelas beiradas sua posição social desvalorizada, agora a reivindicação era feita abertamente.

No que se refere à associação entre empregada doméstica $e$ erotismo, Cheias de Charme buscou enfrentar o tema, tantas vezes já veiculado pela televisão. Manoel Carlos foi o autor responsável por algumas dessas cenas na teledramaturgia brasileira, sempre gerando polêmicas. ${ }^{17} \mathrm{Em}$ Cheias de Charme, a temática foi abordada diversas vezes. A principal delas foi a sequência em que a empregada Penha (Tais Araújo) foi assediada na área de serviço pelo seu patrão, o fotógrafo espanhol Alejandro (Pablo Belini). Diante do assédio, Penha não cedeu, respondendo com um forte tapa na cara do estrangeiro. A escolha dos personagens para viver

varal na frente da casa. Quando a nova patroa chegou, ficou horrorizada e disse que aquilo ali "não era barraco". Luiza se ofendeu; segundo ela, por mais que ela more na favela, "ela acha que tá falando com quem?". Pediu as contas. No terceiro emprego, depois de um mês indo tudo bem, a patroa começou a lhe enviar diariamente torpedos pelo celular com mensagens como "deixar os panos de chão mais brancos", "limpar melhor o piso dos quartos". Luiza conta que achou aquilo "muito chato". Diante de uma oportunidade como auxiliar de limpeza em uma firma, ela pediu demissão. Ganhava menos, mas acreditava que estava valendo a pena por ter as regras mais claras.

${ }^{17}$ Destaca-se a sensual e chantagista empregada doméstica Cida (Thaísa Carvalho), da telenovela Viver a Vida, exibida em 2009, entre outras personagens. 
a cena - Penha, única "empreguete" negra, e Alejandro, o estrangeiro europeu - certamente não foi casual. Conforme destaca Moutinho (2003:169), o par homem branco estrangeiro com mulher negra esteve fortemente relacionado ao ideal de construção da nação brasileira em uma relação de dominação e erotismo. Na televisão, conforme sublinhou Joel Zito Araújo (2004:257) ao analisar os trabalhos realizados por atrizes $e$ atores negros em novelas brasileiras, esse estereótipo da "mulata sensual e sedutora" também foi reencenado diversas vezes. ${ }^{18}$

Em Cheias de Charme, ainda que com sua atitude a personagem Penha parecesse querer revidar essa longa história de abusos sexuais sofridos por trabalhadoras domésticas, também se reencenaram alguns desses estereótipos. Um dos principais figurinos artísticos das "Empreguetes" consistia em uniformes estilizados sobre corpetes de renda, compostos com cintas-ligas pretas. Diluídas nas coreografias e brincadeiras do trio de cantoras que tanto agradaram o público infantil, o apelo erótico dessa vestimenta típica de sex-shops passou quase despercebido pelo público. Também em uma das músicas encenadas pelo trio, intitulada Maria Brasileira, a temática era apresentada de maneira bastante ambígua, reforçando estereótipos ao caracterizá-las como "Marias sem-vergonha". ${ }^{19}$

${ }^{18}$ A associação entre empregadas domésticas e sexualidade também foi amplamente explorada pela pornochanchada brasileira na década de 1970 . Nesse contexto, destacou-se o filme "Como é boa a nossa empregada", de 1973. Nessas e em outras produções, a combinação entre alteridade racial $e$ subordinação de classe e de gênero, associadas à servidão implícita no trabalho doméstico, é o que reforçam, segundo Wade (2013), uma imagem de disponibilidade sexual das trabalhadoras domésticas, especialmente as mais jovens. No trabalho de cuidado de idosos, a sexualidade também tem se revelado uma dimensão importante, conforme destaca Helena Hirata (2016), revelando os persistentes desafios de gênero envolvidos nessas profissões.

${ }^{19}$ A letra de Maria Brasileira, em uma de suas estrofes, diz: "Maria sem-vergonha/ Marias sensuais/ Maria vai-com-as-outras/ Quero ver você fazer o que ela faz". E, mais adiante, novamente toca nessa temática: "Maria na pia/ Maria na feira/ Maria falando e escutando besteira / Maria fingindo que não entendeu os olhares de alguém/ Maria cantando/ Maria dançando/ [...] Maria querendo ser rica também". 
De maneira geral, a associação entre trabalhos domésticos e feminilidade tampouco escapou de alguns estereótipos na trama de Cheias de Charme. Se as telenovelas brasileiras já incorporavam na heroína de classe média o ideal da "super mulher" que dá conta de uma série de tarefas - "têm sua profissão, são economicamente ativas e independentes, têm vida sexual ativa e feliz", além de serem boas mães e esposas (Almeida, 2007:183) - esse ideal agora se espraiava para as demais classes sociais. A personagem Penha foi ilustrativa dessa tendência: empregada doméstica competente, que cuidava de sua casa e se sentia responsável pelo bem-estar de todos os familiares, além de ser vaidosa, bonita, divertida e sensual. Assim, além de cumprir com todas as atividades de sua vida particular - não sem conflitos e sofrimentos -, a personagem ainda garantia o cuidado da casa $e$ dos familiares da patroa, atividades vistas como eminentemente femininas. Talvez o próprio termo "empreguete" - derivado de "piriguete", termo popular ambíguo que remete a um tipo mulher insinuante e "empoderada" - tenha sido apropriado visando esse ideal.

\section{4. "Pé de chinelo" ou de salto alto? Mobilidade social, consumo $e$ autoestima entre as empreguetes}

A ascensão social é tema recorrente nas telenovelas brasileiras. Pode-se dizer, talvez, que sua maior ou menor centralidade varie de acordo com os contextos socioeconômicos nos quais as tramas são produzidas. Segundo Joel Zito Araújo (2004:107), a encenação recorrente da mobilidade social no final da década de 1960 e durante a década de 1970, período que ficou conhecido como o "milagre econômico", não é casual. ${ }^{20}$ Nesse contexto, o arrivista Beto Rockfeller, da trama que levou seu nome

\footnotetext{
${ }^{20}$ De acordo com Araújo, "com exceção das novelas adaptadas de romances clássicos da literatura brasileira, quase todos os sucessos daquele período, quando se referiam a histórias desenroladas no contexto urbano, tinham direta ou indiretamente como temática os efeitos da mobilidade social no destino dos seus personagens" (2004:107).
} 
em 1968, seria bastante expressivo do período (Araújo, 2004; Costa, 2000).

Contextualizada nos anos 2000, marcado por alterações socioeconômicas que incidiram no padrão de vida das classes trabalhadoras brasileiras, Cheias de Charme também retratou o "sonho" da mobilidade social, recolocando-o como um dos principais objetivos de vida. Articulando essa expectativa de ascensão social com marcadores de gênero, sexualidade e raça, a trama chamava a atenção para as negociações possíveis de agência em contextos marcados por desigualdades sociais (Piscitelli, 2008). Assim, quando no primeiro capítulo as protagonistas Penha, Cida e Rosário se conhecem numa delegacia, o pacto ali selado e repetido diversas vezes ao longo da trama já revelava o desejo eminente por ascensão social: "dia de empreguete, véspera de madame!".

Um discurso motivacional acompanhava a empreitada, sendo tema das principais canções do trio. A letra de "Vida de Empreguete", canção que as lançara como cantoras de sucesso na novela e apresentada no início deste artigo, é interessante para compreendermos $\mathrm{o}$ ideal de ascensão social envolvido. ${ }^{21}$ Encontramos aí elencados uma série de pontos importantes para esta análise: a rotina repetitiva da empregada doméstica, a sensação de desvalorização profissional diante dos patrões, o desejo de inversão dos papéis sociais (empregada vira madame $e$ madame vira empregada), o endividamento diante dos gastos com a imagem pessoal (alongamento do cabelo e uso de sapatos de salto alto) e o plano de ascender socialmente, possivelmente virando "socialite". O sonho da "empreguete", nesse caso, passa

\footnotetext{
${ }^{21}$ A letra diz: Todo dia acordo cedo / Moro longe do emprego / Quando volto do serviço, quero o meu sofá / Tá sempre cheia a condução / Eu passo pano, encero chão / A outra vê defeito até onde não há / Queria ver madame aqui no meu lugar / Eu ia rir de me acabar / [...] Minha colega quis botar / Aplique no cabelo dela / Gastou um extra que era da parcela / As filhas da patroa / A nojenta e a entojada / Só sabem explorar, não valem nada [...]. Levo vida de empreguete / eu pego às sete / Fim de semana é salto alto e ver no que vai dar / Um dia compro apartamento e viro socialite / Toda boa, vou com meu ficante viajar.
} 
longe da reivindicação política ou da reforma social. O que ela quer é ascender, consumir, desfrutar e, se possível, não trabalhar.

Para entender a implicação de tais ideais é necessário, em primeiro lugar, localizar esse discurso na mídia que o veicula. A televisão comercial, conforme destaca Heloisa Almeida (2007:179), sempre promoveu o consumo e o desejo por bens. Ao transformar espectadores em consumidores, tal mídia cria novas disposições para o consumo. Indo além dos anúncios publicitários e do merchandising, o próprio texto da novela ensina como usar $e$ combinar uma série de bens, mostrando a importância que apresentam na criação de estilos pessoais (Almeida, 2007:185). Sem ser diferente, Cheias de Charme realizou merchandising de uma série de itens como produtos de limpeza, sapatos e maquiagens. ${ }^{22}$ Também a própria trama realçou a todo momento a importância para a mulher de classe popular de se arrumar e cuidar de seu corpo, de sua casa e de sua família, em uma espécie de pedagogia do consumo.

Essa associação entre consumo, beleza e cuidados pessoais visando a elevação da autoestima e, possivelmente, a ascensão social, é recorrente na indústria cultural e, muito provavelmente, vem se acentuado nesse início de século XXI. Ao discutir o sucesso da revista Raça Brasil no início dos anos 2000 no Brasil, o antropólogo Peter Fry levantou alguns pontos importantes em relação a esse debate. Para os criadores da revista, era papel deles auxiliar o homem e a mulher negros a se embelezarem. Tal como feito em uma série de revistas de beleza não segmentadas pela cor da pele, esse produto ajudaria esse segmento a conseguir melhores posições no mercado de trabalho e no mercado eróticoafetivo. Segundo Fry (2005:266), os agentes do mercado estavam "convencidos de que um aumento da beleza leva a um aumento

\footnotetext{
${ }^{22} \mathrm{O}$ merchandising da marca de cosméticos Avon, por exemplo, foi bastante repetido. Lutando, provavelmente, contra a pecha de marca utilizada no Brasil sobretudo por integrantes das classes populares, na trama quem utilizava o creme contra envelhecimento era a distinta advogada Dra. Ligia, uma das patroas retratadas. Também as empreguetes, quando famosas, passaram a usar essa marca de maquiagem.
} 
da autoestima". Se, nas disputas por empregos e por parceiros sexuais, a aparência seria importante para todos, tornava-se fácil compreender o sucesso da revista. Desse modo, ao promover a beleza negra de classe média e a autoestima desse segmento, a revista Raça Brasil terminaria por ter um papel político, o de enfrentar a discriminação e a desigualdade, "ainda que dentro da ordem social existente" (Fry, 2005:268).

Assim, do mesmo modo como a revista Raça Brasil, por meio de um exercício mercadológico, esforçou-se para "valorizar" o homem e a mulher negros de classe média pelo reforço positivo em sua autoestima, Cheias de Charme buscou promover as empregadas domésticas por meio de fórmula similar: as trabalhadoras domésticas podem ser bonitas, alegres $e$ consumidoras. Mais do que podem, elas devem deixar para trás o "pé de chinelo" e incorporar o sapato de salto alto, numa atitude autoafirmativa proporcionada pela aparência e pelo consumo de bens. Tal propósito foi explícito. Isabel Oliveira, autora da trama, destacou que era sua intenção retratar as empregadas domésticas como integrantes da "classe C em ascensão" e assim, "falar da autoestima dessa classe" (Globo, 2012; grifo meu).

Talvez seja essa a chave para compreendermos a mensagem central dessa telenovela. Ao representar empregadas domésticas bonitas, bem vestidas, otimistas, possuidoras de itens de consumo de última geração e de casas bem decoradas (ainda que na favela), as diferenças entre a "empreguete" e a "madame" pareceriam menos pronunciadas $e$, a qualquer momento, superáveis. Assim, ao invés da antiga desigualdade social brasileira naturalizada e intransponível, encenava-se uma desigualdade conjuntural e passageira. Desse modo, se essa mulher a qualquer momento tiver a oportunidade de mudar de vida (por meio do estudo, do trabalho ou graças a um golpe de sorte), ela será igual às "madames" $e$, ao menos no plano da aparência (que, na verdade, é o que mais importa, ao lado do bom caráter), já estaria praticamente pronta para a nova posição. Para embasar tal mensagem, Cheias de Charme conseguiu engenhosamente unir o contexto socioeconômico propício, de maior mobilidade social da 
"nova classe C", com um plano universal, típico das fábulas, tal qual Cinderela. Assim, entender a renovação das representações das empregadas domésticas nessa telenovela requer compreender também os interesses de mercado aí embutidos. ${ }^{23}$ Ou seja: as "empreguetes" de Cheias de Charme puderam reivindicar direitos trabalhistas, respeito e cidadania no "mundo ficcional" por terem se constituído no "mundo real" como consumidoras a serem levadas a sério.

Em minha pesquisa de campo, a empregada doméstica Maria Lucia, em especial, era uma mulher que investia em sua autoimagem assim como as "empreguetes" da televisão. Então com 33 anos, procurava vestir-se bem, de maneira moderna $e$ jovem, com muitos acessórios, maquiagem e tatuagens de estrelas nos ombros. Gostava de "se arrumar" a ponto de ser confundida com uma possível "patroa" nos ires e vires da cidade, conforme relatou certa vez. Assim, acabou por criar uma forte identificação com a protagonista Rosário (Leandra Leal). Segundo Maria Lucia, ao lutar pelo sonho de tornar-se cantora famosa, a personagem revelou ser uma mulher que "quer conquistar coisas", "quer ir além", como ela. Ambas eram vaidosas e gostavam de andar na moda. Resumindo, eram "parecidas". Maria Lucia afirmava: "não é que eu queira ser mais do que eu sou, viver em outro mundo, mas é querer subir, querer ir pra cima". Ao contrário de Rosário, entretanto, Maria Lucia não possuía talentos musicais e não havia concluído o ensino médio. $\mathrm{O}$ investimento na aparência pessoal era, por ora, sua única e melhor estratégia. Ainda assim, foi Maria Lucia quem chamou a atenção para esse ponto importante sobre a telenovela. Segundo sua análise sobre a trama, apesar de não retratar tão bem a "realidade" do emprego doméstico, o folhetim

\footnotetext{
${ }^{23}$ Se em Cheias de Charme foi possível identificar mudanças no que se refere à representação de classe social, em relação à cor/raça não ocorreram transformações similares. Se, por um lado, a telenovela visibilizou diversas atrizes negras em papeis secundários, por outro, o triplo protagonismo teve apenas uma atriz negra (Tais Araújo), quem (ao lado de Camila Pitanga) assumiu quase todos os papéis de destaque para personagens negras em produções recentes da Rede Globo.
} 
tinha o importante papel de mostrar aos patrões que aquela pessoa que estava lhe servindo é empregada doméstica hoje, mas a qualquer momento pode mudar de vida ("pode ser outra coisa amanhã"), possivelmente frequentando os mesmos ambientes $e$ vestindo as mesmas roupas que eles. Diante da desigualdade social entre patrões e empregadas, por muito tempo naturalizada no Brasil, a encenação da mobilidade social dessas profissionais cumpria assim seu papel de desestabilizar, ao menos no plano simbólico, essa estrutura.

No entanto, se Maria Lucia entregava-se a essa ideologia de maneira mais direta, a análise resignada da diarista Maria, conforme comentarei a seguir, tornava mais claro o mecanismo artificioso aí entrelaçado.

\section{Os sonhos de Maria e o espelho mágico ${ }^{24}$}

No contexto das interlocuções realizadas, as análises de Maria sobre a telenovela e sobre sua própria vida trouxeram um contraponto, permitindo perceber como esse discurso, embora pertinente, deve ser relativizado diante da realidade social brasileira à qual se refere. Seja na ficção, seja na vida real, para além das progressivas transformações que vêm ocorrendo no emprego doméstico - incluindo novos direitos trabalhistas $e$ incremento da renda no período ${ }^{25}$ - é preciso também enxergar as

\footnotetext{
${ }^{24}$ Espelho mágico, além da referência ao universo dos contos de fadas, foi também o nome de uma telenovela exibida pela Rede Globo em 1977 que, por meio do recurso à metalinguagem, explorava a tensão entre ficção e realidade no universo televisivo. A trama teve autoria de Lauro César Muniz; Vera Fischer interpretou uma atriz de pornochanchada que desejava mudar o rumo de sua carreira (Memória Globo, 2010). Aqui, ao mobilizar o "espelho mágico" do universo das fábulas, quero enfatizar justamente essa fronteira instável entre "ficção" e "realidade" no processo de produção e recepção de Cheias de Charme.

${ }^{25}$ No período de realização da pesquisa (2010 a 2013) ocorreram algumas transformações muito relevantes. Foi aprovada a "PEC das Domésticas" (Emenda Constitucional 72/2013) que equiparou os direitos dos empregados domésticos aos dos demais trabalhadores. A PEC estendeu aos trabalhadores
} 
desigualdades que permanecem, tendo como eixo marcadores sociais da diferença como gênero, raça e classe social (Macedo, 2015).

Ao longo da pesquisa, a situação socioeconômica de Maria $e$ de seus familiares se tornou mais difícil. Sua mãe ficou doente, $e$ ela a trouxe de Minas Gerais para sua casa. Sem muita opção, teve de abrir mão de todos os dias de faxina, exceto dos sábados, para cuidar dela. O marido, descontente com a sogra na residência, alongou seus períodos no bar após o serviço. Ainda sem o cadastro no Bolsa Família (ela esperava por meses), passou a depender da aposentadoria da mãe e da boa vontade do esposo. Com o dinheiro curto, enfurnada em casa com as crianças em uma favela de Diadema (SP), o lazer de Maria restringiu-se, ainda mais, à televisão, e ela se entregou de vez a esse "éter caseiro" (Miceli, 2005).

Maria, assim, alternava sua rotina entre os trabalhos domésticos em sua própria casa, a televisão e os sonhos. Quando jovem, sonhara em ser atriz de televisão. Mais recentemente, sonhava em ter uma casa grande, em bairro que não fosse favela, com uma suíte para cada membro da família. Sonhava com um marido que a tratasse com afeto e lhe levasse para viajar. Também almejava um futuro melhor para os filhos, possivelmente vendo-os cursar o ensino superior. Grande parte de nossas conversas em sua cozinha eram sobre isso. Para tanto, enviava cartas a programas de auditório que prometem o sonho da casa própria $e$ realizava "campanhas" pagas na igreja evangélica que frequentava, em busca de pequenos milagres. Suas chances de conquistar tais sonhos eram pequenas (exceto, talvez, pelo futuro dos filhos menores), e ela, no fundo, sabia disso.

Cheias de Charme, sem ser diferente de tantas outras telenovelas que ela já acompanhara na vida, encaixava-se nesse

domésticos o limite de 44 horas semanais e 8 horas diárias, além da obrigatoriedade do pagamento de horas extras, adicional noturno e FGTS. Também os salários tiveram aumento acima da inflação no período: cerca de 12\%, em 2012, e 11\% em 2013 (Soares, 2014). Ainda assim, seguia sendo uma das piores remunerações do mercado de trabalho brasileiro. 
seu universo de projeções. Assim, no segundo capítulo, Maria já resumia: "a novela é sobre empregadas que gostam de sonhar, né? E quem não gosta?", recorrendo à associação entre projeções e fantasias, tão recorrente entre espectadoras de televisão: "fantasia e ficção são os espaços do excesso, seguros, que existem nos interstícios da vida social ordenada" (Ang, 1996:95).

Porém, quem mais marcou Maria na telenovela Cheias de Charme foi o personagem de um rico advogado, chamado Dr. Otto Werneck. Ao longo da trama, cada vez que eu ia a sua casa conversar ou assistir conjuntamente à novela, ela dizia "que coroa o Dr. Otto, hein?", "bonito, educado...". E brincava, "um coroa desses não brota na minha horta!". Maria, com seu humor de sempre, estava bastante envolvida. No último capítulo, diante das minhas perguntas sobre sua opinião para tal ou qual desfecho, ela só queria conversar sobre o relacionamento entre Dr. Otto $e$ Ivone, empregada doméstica evangélica que, então maquiada $e$ bem vestida, sorria a todos mostrando que se tornara a respeitável esposa do distinto advogado. Durante a cena, Maria exclamava ao ver a coadjuvante: "ela merece!", "ela ficou mais linda que as outras!". Entregando-se a esse romance, Maria via, mais uma vez na televisão, um espelho mágico: Ivone, afinal, era exatamente como ela nos tais sonhados sonhos, gata borralheira transfigurada em Cinderela.

Após meses de convivência mais ou menos frequente, assisti juntamente com seus dois filhos menores ao tão esperado último capítulo de uma novela. No show de despedida das Empreguetes, as protagonistas, três Marias, declararam: "essa foi uma homenagem a todas as Marias desse país. Quem é Maria levanta a mão?”. Na cama, os filhos de Maria, brincando, agitados diante de minha presença, gritavam, "minha mãe é Maria!, minha mãe é Maria!". Maria sorriu, contente e irônica, diante da homenagem que a Rede Globo lhe proporcionava. Com o fim do episódio, as crianças mudaram de canal e Maria foi para a cozinha esquentar a janta. A rotina rapidamente se refazia. Sem maquiagem, salto alto ou qualquer outra mostra de glamour, era mesmo naquela cozinha simples que sua vida seguia. Filha de uma longa geração de 
agricultores pobres, para Maria, a pobreza e a desigualdade social não foram vencidos na cidade grande. Mas dali a pouco começaria outra novela; amanhã outra, e depois outra. E, pelo menos por ora, na vida dura dessa Maria, pouca coisa mudava.

\section{Referências bibliográficas}

AlmeidA, Heloisa Buarque de. Telenovela, Consumo e Gênero: "muitas mais coisas". Bauru, Edusc, 2003.

Consumidoras e heroínas: gênero na telenovela. Revista Estudos Feministas, v.15, 2007, p.177-92.

AlmEIDA, Heloisa; MACEDO, Renata. Discursos sobre a novela classe média na mídia: classe, gênero e raça em intersecção. In: $39^{\circ}$ Encontro Anual da Anpocs, outubro de 2015, Caxambu-MG.

ANG, Ian. Living room wars: rethinking media audiences for a postmodern world. Londres e Nova Iorque, Routledge, 1996.

ARAÚJO, Joel Zito. A negação do Brasil: o negro na telenovela brasileira. São Paulo: Ed. Senac. 2004.

BARTelt, Dawid (org). A "nova classe média" no Brasil como conceito e projeto político. Rio de Janeiro, Fundação Heinrich Böll, 2013.

Bourdieu, Pierre. A Distinção: crítica social do julgamento. São Paulo, Edusp, 2007.

BRITES, Jurema. Afeto e desigualdade: gênero, geração e classe entre empregadas domésticas e seus empregadores. cadernos pagu (29), Campinas, Núcleo de Estudos de Gênero-Pagu/Unicamp, 2007, pp.91-109.

BRITES, Jurema; PICANÇO, Felícia. O emprego doméstico no Brasil em números, tensões e contradições: alguns achados de pesquisas. Revista Latino-americana de estudos do trabalho, ano $19, \mathrm{n}^{\circ} 31$, 2014, pp.131-158.

CostA, Cristina. A milésima segunda noite: da narrativa mítica à telenovela. São Paulo, AnnaBlume, 2000. 
ESCOURA, Michele. Girando entre princesas: performances e contornos de gênero em uma etnografia com crianças. Dissertação (Mestrado em Antropologia Social), Universidade de São Paulo, 2012.

FELTRIN, Ricardo. Globo muda telejornal para tentar salvar ibope e atrair classe C. Folha de S. Paulo, 22 jun. 2011 [http://www1.folha.uol.com.br/ilustrada/933102-globo-mudatelejornal-para-tentar-salvar-ibope-e-atrair-classe-c.shtml - acesso em: 11 abr. 2013].

FONSECA, Claudia. O anonimato e o texto antropológico: dilemas éticos e políticos da etnografia "em casa". In: SCHUCH; VIEIRA; PETERS (orgs). Experiências, dilemas e desafios do fazer etnográfico contemporâneo. Porto Alegre, Ed. da UFRGS, 2010, pp.205-227.

FRY, Peter. Política: relações entre "raça", publicidade e produção da beleza no Brasil. In: __. A persistência da raça: ensaios antropológicos sobre o Brasil e a África Austral. Rio de Janeiro, Civilização Brasileira, 2005, pp.249-271.

GLOBO. Cheias de charme: uma homenagem a mulher guerreira de todas as classes. Site Globo.com. 04/04/2012 [http://tvg.globo.com/novelas/cheias-de-charme/Fique-pordentro/noticia/2012/04/cheias-de-charme-uma-homenagem-mulherguerreira-de-todas-classes.html - acesso em: 08 abr. 2012.

GRIMM, Jacob; GRIMM, Wilhelm. Contos maravilhosos infantis e domésticos - 1812-1815. São Paulo, Cosac Naify, 2012.

HALl, Stuart. Da diáspora: identidades e mediaçôes culturais. Belo Horizonte, Ed. UFMG, 2003.

HAMBURGER, Esther. O Brasil antenado: a sociedade da novela. Rio de Janeiro, Jorge Zahar Ed, 2005.

. A vingança da empregadinha. O Estado de S. Paulo, São Paulo, 29 jul 2012 [http://www.estadao.com.br/noticias/impresso,a-vingancada-empregadinha, 907513,0.htm - acesso em: 07 mar. 2013].

HIRATA, Helena. Subjetividade e sexualidade no trabalho de cuidado. cadernos pagu (46), Campinas, Núcleo de Estudos de GêneroPagu/Unicamp, jan-abril de 2016, pp.151-163. 
IG. As melhores e as piores audiências das novelas das 19h. 16/06/2012. [http://gente.ig.com.br/2012-06-16/as-melhores-e-as-pioresaudiencias-das-novelas-das-19h.html - acesso em: 07 mar. 2013].

JIMENEZ, Keila. Atrás da classe C, TV fatura $12 \%$ a mais no semestre. Folha de S. Paulo, São Paulo, 09 jul 2012 [http://www1.folha.uol.com.br/colunas/outrocanal/1117251-atras-daclasse-c-tv-fatura-12-a-mais-no-semestre.shtml - acesso em: $11 \mathrm{abr}$. 2013].

KOFES, Suely. Mulher, mulheres: identidade, diferença e desigualdade na relação entre patroas e empregadas domésticas. Campinas, Editora da Unicamp, 2001.

LIMA, Marcia; REZENDE, Claudia. Linking gender, class and race in Brazil. Social Identities, vol. 10, n 6, 2004, pp.757-773.

MACEDO, Renata Mourão. Espelho mágico: empregadas domésticas, consumo e mídia. Dissertação (Mestrado em Antropologia), Universidade de São Paulo, 2013.

Trabalho doméstico, consumo e interseccionalidade: possibilidades de agência na trajetória de uma (ex) empregada doméstica. Revista Mediaçóes, vol. 20, Londrina, 2015, pp.184-207.

MARINHEIRO, Vaguinaldo. Todos querem tirar a nova classe média para dançar. Folha de São Paulo, São Paulo, 15 jul. 2012 [http://www1.folha.uol.com.br/ilustrissima/1119929-todos-queremtirar-a-nova-classe-media-para-dancar.shtml - acesso em: 11 abr. 2013].

MELO, Max. Dia de empreguete, véspera de madame: permanências e rupturas na construção da personagem doméstica em Cheias de Charme. In: XXXIX Congresso Brasileiro de Ciências da Comunicação, 05 a 9 de set. 2016, São Paulo, SP.

Miceli, Sergio. A Noite da Madrinha e outros ensaios sobre o éter nacional. São Paulo, Companhia das Letras, 2005.

MIRA, Maria Celeste. O circo eletrônico: Silvio Santos e o SBT. São Paulo, Edições Loyola; Ed. Olho D’água, 1995.

MEMÓRIA Globo. Guia ilustrado TV Globo: novelas e minisséries. Rio de Janeiro, Jorge Zahar, 2010. 
MoUTiNHO, Laura. Razão, "cor" e desejo: uma análise comparativa sobre relacionamentos afetivo-sexuais "inter-raciais" no Brasil e na África do Sul. São Paulo, Ed. Unesp, 2003.

NATELINHA. Cheias de Charme bate recorde de audiência no Rio de Janeiro. 18 jul.

2012 [http://natelinha.uol.com.br/noticias/2012/07/18/cheias-de-charmebate-recorde-de-audiencia-no-rio-de-janeiro-162342.php - acesso em: 07 mar. 2013].

NERI, Marcelo (coord). A nova classe média: o lado brilhante dos pobres. Rio de Janeiro, FGV/CPS, 2010 [http://www.cps.fgv.br/ibrecps/ncm2010/NCM_Pesquisa_FORMATAD A.pdf - acesso em: 02 set 2016].

PISCITELLI, Adriana. Interseccionalidades, categorias de articulação e experiências de migrantes brasileiras. Sociedade e Cultura, vol. 11, $\mathrm{n}^{\circ}$ 2, jul/dez 2008, pp.263-274.

REZENDE, Claudia B. A empregada na televisão: uma pequena análise sobre representações. Cadernos de Antropologia e Imagem, vol. 5(2). 1997.

SAFFIOTI, Heleieth. Emprego doméstico e capitalismo. Petrópolis, Ed. Vozes, 1978.

SCAlON, Celi; Salata, André. Uma nova classe média no Brasil da última década? O debate a partir da perspectiva sociológica. Revista Sociedade e Estado, vol. 27, n², 2012, pp.387-407.

SINGER, André. Os sentidos do lulismo: reforma gradual e pacto conservador. São Paulo, Companhia das Letras, 2012.

SOARES, Pedro. Doméstico pesa mais no gasto das famílias. Folha de São Paulo, São Paulo, 02 mar. 2014 [http://www1.folha.uol.com.br/mercado/2014/03/1420008sdomestico-pesa-mais-no-gasto-das-familias.shtml - acesso em: 14 mar. 2014].

SouZA, Jessé. Os batalhadores brasileiros: nova classe média ou nova classe trabalhadora? Belo Horizonte, Ed. UFMG; Humanitas, 2010.

STYCER, Mauricio. Globo muda programação para atender a nova classe C. 09 maio 2011 [http://televisao.uol.com.br/ultimas- 
noticias/2011/05/09/globo-muda-programacao-para-atender-a-novaclasse-c.jhtm - acesso em:11 abr. 2013].

VAREla, Mirta. Recepción. In: AltamiRAno, Carlos (org.) Terminos críticos de sociología de la cultura. Buenos Aires, Paidós, 2008, pp.195-198.

WADE, Peter. Articulations of eroticism and race: domestic service in Latin America. Feminist Theory, vol. 14, n² 2, 2013, pp.187-202. 